\title{
Design and Operation of Optical Fiber for Mass Measuring Instrument with Bending Power Loss Principle
}

\author{
Saktioto ${ }^{1}$, Wahyu Candra ${ }^{1}$, Vepy Asyana ${ }^{1}$, Romi Fadli Syahputra ${ }^{1}$, Syamsudhuha ${ }^{2}$, Dedi Irawan ${ }^{3}$, \\ Okfalisa $^{4}$, Haryana Hairi ${ }^{5}$, Dadang Syarif Shihabudin Sahid ${ }^{6}$ \\ ${ }^{1}$ Department of Physics FMIPA, Universitas Riau, Pekanbaru, Indonesia \\ ${ }^{2}$ Department of Mathematics FMIPA, Universitas Riau, Pekanbaru, Indonesia \\ ${ }^{3}$ Physics Education FKIP, Universitas Riau, Pekanbaru, Indonesia \\ ${ }^{4}$ Department of Informatics Engineering, UIN Sultan Syarif Kasim Riau, Indonesia \\ ${ }^{5}$ Applied Physics Dept., Universiti Teknologi MARA, Pasir Gudang, Johor, Malaysia \\ ${ }^{6}$ Politeknik Caltex Riau, Pekanbaru, Indonesia
}

\begin{tabular}{l} 
Article Info \\
\hline Article historys: \\
Received May 5, 2020 \\
Revised Mar 16, 2021 \\
Accepted May 17, 2021 \\
\hline
\end{tabular}

\section{Keywords:}

Macro-bending

Single-mode fiber

Mass measuring instrument

Round trip

Correlation coefficient

\begin{abstract}
Utilization fiber optics macro-bending will be useful for non-destructive applications, such as a mass measurement device. This research, therefore, analyzes the fiber optic power loss due to macro bending by mass loading and explores its possible application as an instrument of mass scale. A single-mode fiber (SMF) with a core diameter of $8.2 \mu \mathrm{m}$ and laser with a wavelength of $1310 \mathrm{~nm}$ and $1550 \mathrm{~nm}$ are used in this work. Moreover, an optical power meter with a sensitivity of $0.01 \mathrm{dBm}$ is applied as the detector while power loss is determined using nine bending cylinders that can produce eighteen bends with a roundtrip system. It is obtained a correlation coefficient $R^{2}$ of 0.9910 and 0.9959 corresponding to a sigmoid of 4 parameters for two-wavelength sources of $1310 \mathrm{~nm}$ and $1550 \mathrm{~nm}$, respectively. The results showed mass suppression can produce a power loss with a relatively small error of $19.60 \%$, $11.23 \%, 0.20 \%, 3.74 \%$, and $9.36 \%$ for mass $300 \mathrm{~g}, 600 \mathrm{~g}, 100 \mathrm{~g}, 1400 \mathrm{~g}$, and $1800 \mathrm{~g}$, respectively.
\end{abstract}

Copyright () 2019Institute of Advanced Engineering and Science. All rights reserved.

\section{Corresponding Author:}

Saktioto,

Department of Physics FMIPA,

Univeristas Riau,

Bina Widya Campus, Jl. HR Soebranas KM 12,5 Pekanbaru 28293, Riau, Indonesia

Email: saktioto@yahoo.com; saktioto@lecturer.unri.ac.id

\section{INTRODUCTION}

The use of optical fiber as a data transmission medium cannot be associated with the power losses causing loss of signal. There are some inevitable ones, however, and an example involves macro bendingrelated cases where optical fiber is tangled with a radius larger than the core radius [1]. This further leads to variations in the core and cladding refractive index to produce changes in the direction of light propagation which consequently causes power losses [2]. It is important to note that the amount of the power lost is proportional to the level of curvature received by the optical fibers and this means it is possible to obtain the desired amount through the adjustment of curve magnitude [3]. Moreover, since it is possible to produce the curvature by loading the mass, the amount incurred is also proportional to this mass. This, therefore, means power loss has the potential to be used as a mass measurement instrument but the process requires several criteria including range, sensitivity, and accuracy to ensure efficiency [4]. This fiber-optic measuring instrument offers several benefits, including electromagnetic resistance [5] and electrical interference [6].

The macro-bending in the communication system produces power losses [7] as a side effect but these are utilized as a basic principle for the production of the mass-scale instrument. This involves the deliberate creation of a macro-bending to cause to make fiber optic lose power and this loss increases with the level of 
the bending. However, as previously stated, there is a direct relation between bending and mass loading such that the imposition of a greater load leads to the loss of more power [8].

This research was conducted to investigate the power loss in a single-mode fiber by using macrobending as a mass scales instrument. However, the instrument was tested for eligibility by loading it with different masses. Moreover, the power loss was increased by making two optical fiber lines with a roundtrip system which allowed the nine curved cylinders designed to produce eighteen curves. This was necessary to increase the sensitivity of the instrument without increasing its dimensions.

\section{RESEARCH METHOD}

\subsection{Light propagation in fiber optics}

Figure 1 shows the macro-bending in the optical fiber causes the normal lines to change in position. For example, when the angle of the incident ray is smaller than the critical angle, the ray is projected out of the core [9]. This bending occurs only if the optical fiber is warped beyond the critical radius of the curvature due to a significant change in the amount of power loss which is calculated [10] using the following Equation [11]:

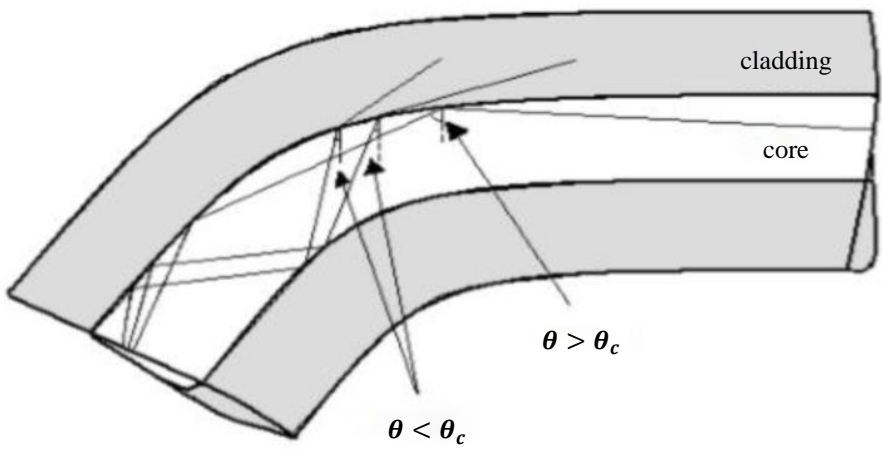

Figure 1. Light propagation inside fiber optic core due to macro-bending [9].

$$
R_{C}=\frac{20 \lambda}{\left(n_{1}-n_{2}\right)^{\frac{3}{2}}}\left(2.748-0.996 \frac{\lambda}{\lambda_{c}}\right)^{-3}
$$

where $R_{c}$ is the critical radius, $n_{1}$ is the core refractive index, $n_{2}$ is the cladding refractive index, $\lambda$ is the transmission wavelength, and $\lambda_{c}$ is the cut-off wavelength of single-mode fiber (SMF) which is $1260 \mathrm{~nm}$.

The bending compresses the inside of the SMF and attracts the outer part longer to change the density of the material. This further causes a change in the refractive index in SMF and consequently in the trajectory of a beam of light. However, the magnitude of changes in the refractive index of the cladding and core can be calculated using Equations (2) and (3) respectively [12].

$$
\begin{gathered}
n_{\text {clad }}^{\prime}=n_{\text {clad }}\left(1+\frac{a}{R_{\text {eff }}}\right) \\
n_{\text {core }}^{\prime}=n_{\text {core }}\left(1+\frac{a}{R_{\text {eff }}}\right)
\end{gathered}
$$

where $R_{\text {eff }}$ is the effective curvature radius and for optical fiber silica $\left(\mathrm{SiO}_{2}\right)$ it is $1.28 R$. The factor 1.28 is the elasto-optic correction factor [13].

Geometrical change in fiber optic due to macro bending leads to a change in the propagation of light $[14,15]$ and is calculated using Equation (4) [16].

$$
L=10 \log \left(\frac{P_{i}}{P_{o}}\right)
$$

where $P_{i}$ is the input power and $P_{o}$ is the output power. 


\subsection{Prototype design}

The optical experiment was conducted on the SMF with the core and cladding refractive indices recorded to be 1.6499 and 1.6440 , respectively. The power loss was analyzed using a mass loading in a range of $50-2000 \mathrm{~g}$ with a $50 \mathrm{~g}$ increament. Moreover, the design and schematic diagram of the mass scale are presented in Figures 2 and 3 respectively.

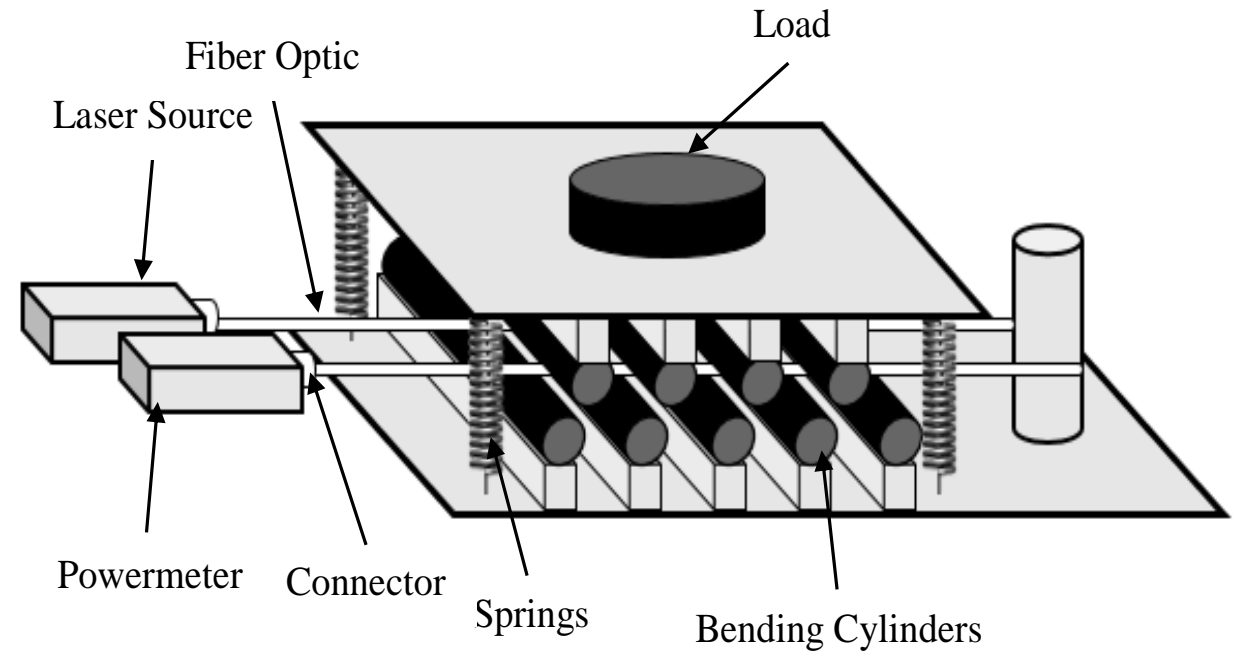

Figure 2. Schematic diagram of the prototype

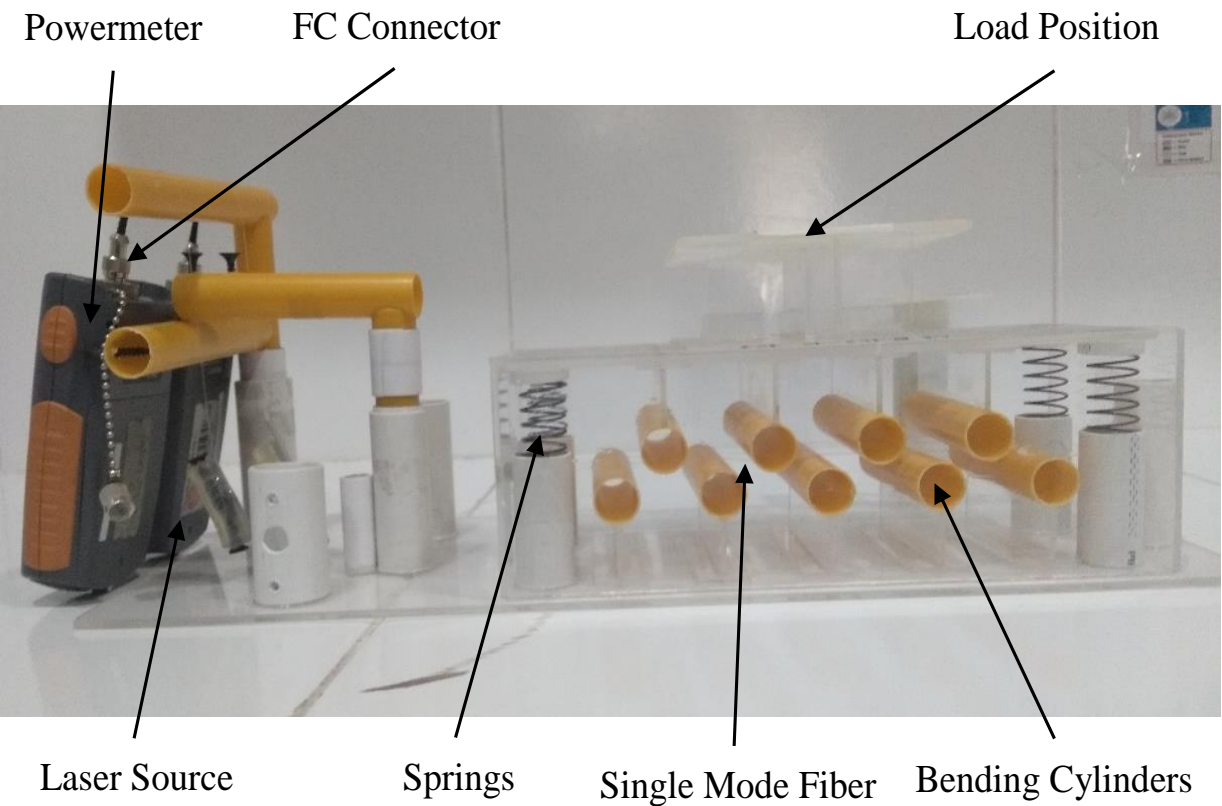

Figure 3. Mass scale instrument design.

This mass-scale instrument consists of nine curved cylinders with a radius of 8mm causing power losses with five fixed to be static at the bottom and four fixed to be dynamic at the top. Moreover, the SMF was produced with a roundtrip system to improve the number of power losses without increasing the number of curved cylinders as previously described. This design was expected to increase the sensitivity of the instrument without increasing its geometry.

An increase in power loss was observed as a load with a certain mass was placed on the top of the scale instrument because the cylinder located there was pressed down. The result found in the middle of the warping was calculated using Equation (4). Meanwhile, the model was created using SigmaPlot ${ }^{\circledR}$ to predict the relationship between power losses and the mass while the level of accuracy of the equation formulated was 
determined using the correlation coefficient $R^{2}$ such that as its value approaches 1 , the result of the equation becomes more accurate.

\section{RESULTS AND DISCUSSION}

\subsection{Measurement ranges}

The mass was measured by dividing the changes in the output power by the input power due to the mass loading on the scale instrument with the state of reference set before it was loaded. In this situation, the SMF that has not experienced curvature was used as the calibrating instrument while the effects of the power losses were measured on two-wavelength variations of $1310 \mathrm{~nm}$ and $1550 \mathrm{~nm}$. For the first variation of $1310 \mathrm{~nm}$, the results showed a very small power loss approximated at $0.01 \mathrm{~dB}$ for every additional $50 \mathrm{~g}$ mass and this means the scale was unstable. This was associated with the $8 \mathrm{~mm}$ radius of the curved cylinder which was adjudged not to be suitable for the wavelength. The average power losses due to the mass loading from the five measurements are shown in Figure 4.

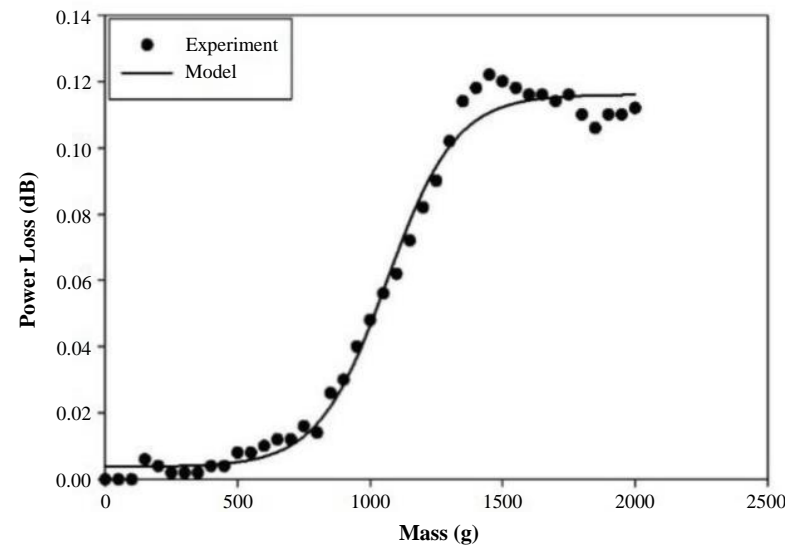

Figure 4. Power losses due to mass loading at a wavelength source of $1310 \mathrm{~nm}$

The dotted graph is the average data from the five measurements while the solid one is the model created to predict experimental data and the result obtained for the $1310 \mathrm{~nm}$ wavelength was calculated using Equation $(5)$,

$$
M=-130 \ln \left(\frac{0.12-L_{m}}{3595 L_{m}-13.66}\right)
$$

where $M$ is the mass of the desired load ( $\mathrm{g})$ and $L_{m}$ is the power loss due to macro-bending (dB).

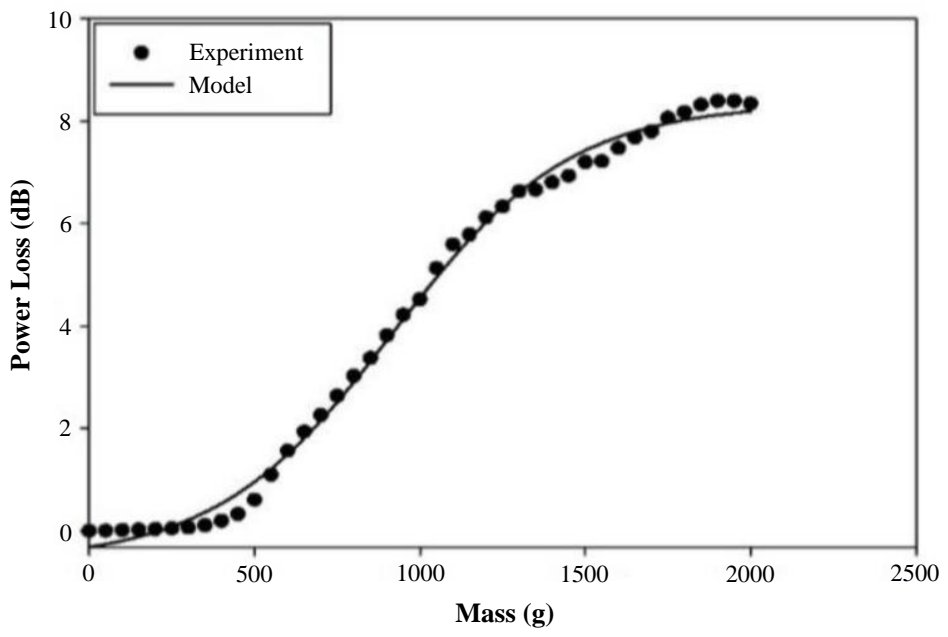

Figure 5. Power losses due to mass loading at a wavelength of $1550 \mathrm{~nm}$

Figure 5 describes the power losses at 1550nm and the results showed the data generated were stable in comparison with those of $1310 \mathrm{~nm}$ and produced a quite significant change in power losses approximated at 
$0.4 \mathrm{~dB}$ for every $50 \mathrm{~g}$ increment and this means it is possible to use this wavelength source in measuring mass scale. The predicted results obtained at this wavelength was calculated using Equation (6),

$$
M=-268 \ln \left(\frac{8.34-L_{m}}{31 L_{m}+18.17}\right)
$$

The graph model was set in the form of a sigmoid with 4 parameters and was observed to have reached a saturation state at a certain point where there was no change in the measured variable. For $1310 \mathrm{~nm}$, it was achieved at the masses above $1,500 \mathrm{~g}$ as indicated by the lack of change or a possible decrease in the power losses as the mass increased. This quick attainment of saturation at his wavelength was associated with the very small power losses change recorded for each additional mass [17]. Meanwhile, at 1550nm, it was achieved at $1,900 \mathrm{~g}$ and this was related to the balance state of the mass at the upper and lower curved cylinders. In this case, despite the continuous increase in the mass scale, significant power losses were not produced because there was no further bending of the optical fiber [18]. However, there were no significant changes in the power losses for the results obtained for masses under $500 \mathrm{~g}$ due to the lack of variations in the refractive index because the optical fiber had not experienced optical strain. A bending factor was recorded and this produced a very low power loss [19].

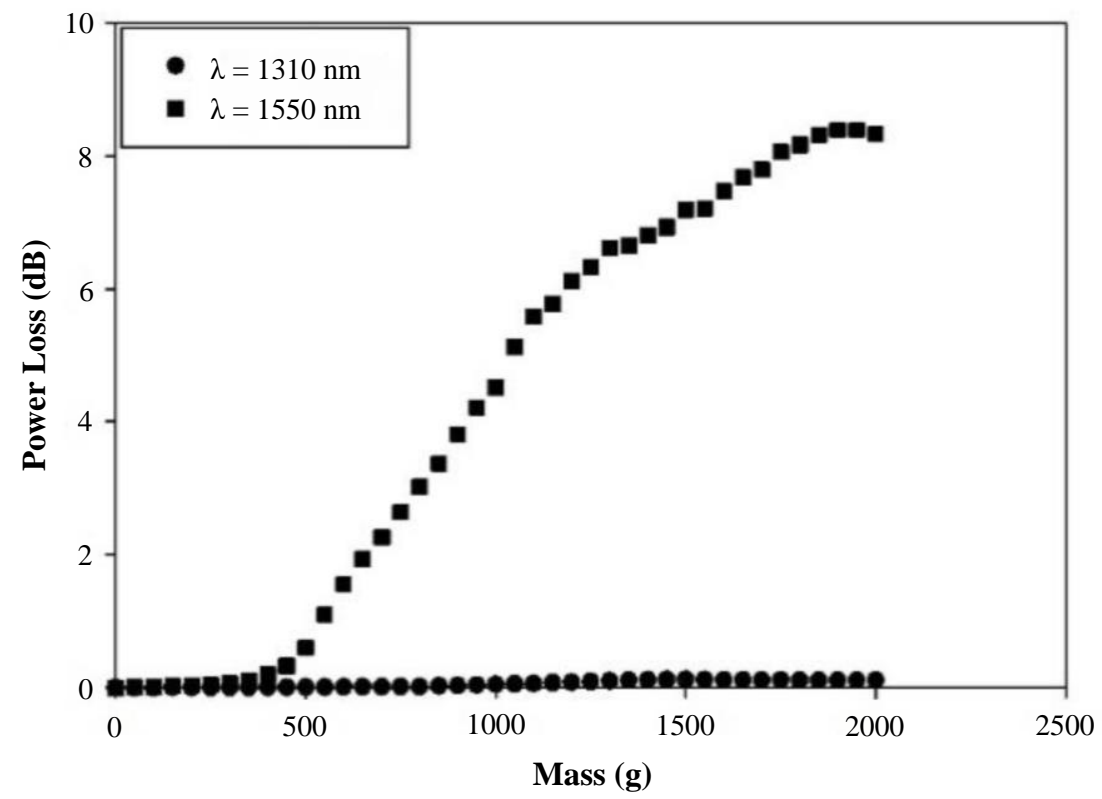

Figure 6. Changes in power losses due to mass loading at a wavelength of $1310 \mathrm{~nm}$ and $1550 \mathrm{~nm}$

The change in power losses at a wavelength of $1550 \mathrm{~nm}$ was found to be greater than at $1310 \mathrm{~nm}$ for the same increment of mass, as depicted in Figure 6. This shows wavelength influences the change in power losses. The use of a greater wavelength led to the loss of more light in the optical fiber core due to the structural changes in the material caused by the macro curvature and this further led to the production of smaller output power. The phenomenon has also been reported to be caused by the scattering [20] and absorption of infrared light by the molecule itself [21].

The changes in the power losses indicated the beginning of the measurements for the masses above $500 \mathrm{~g}$. Mechanically, the fiber strain occurred when the load reached $500 \mathrm{~g}$ below which was not effectively suppressed thereby causing small changes in power losses. Meanwhile, the increase in the mass was observed to have led to an increase in the power loss which further caused the pressing of more spring down and a greater strain in the optical fiber [22]. However, the continuous addition of more mass beyond the strain capacity would make the optical fiber break. Moreover, the length of the optical fiber subjected to warping has also been reported to affect the number of power losses because as the length of the curve increases, more power is directly lost [23]

\subsection{Fitting curve and error analysis}

A fitting curve of retrieved data has been done by sigmoid curve with four parameters. It is obtained a correlation coefficient $R^{2}$ for $1310 \mathrm{~nm}$ and $1550 \mathrm{~nm}$ to be 0.9910 and 0.9959 respectively. This, therefore, means there was more sensitivity at $1550 \mathrm{~nm}$ due to the closeness of its value to 1 . 
The mass scale test was also completed to determine the potential use of SMF as a measurement instrument. It was conducted at $1550 \mathrm{~nm}$ due to its higher sensitivity and change in power loss and the results produced due to loading on the scale were converted to mass using Equation (6).

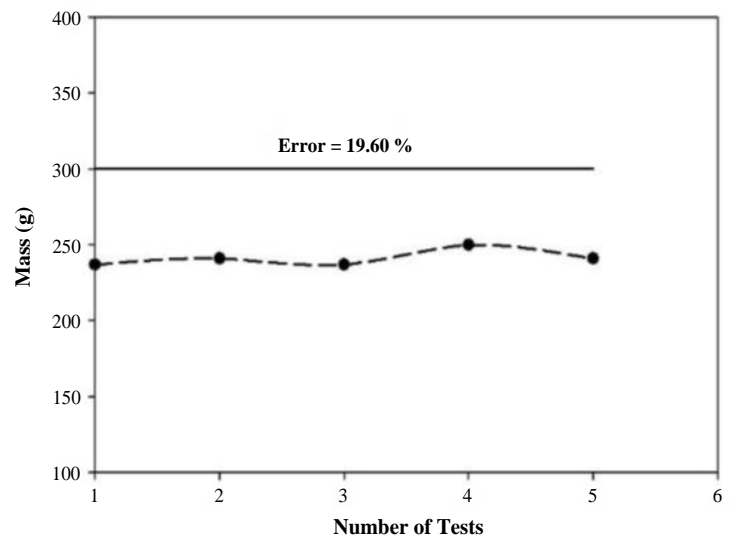

(a)

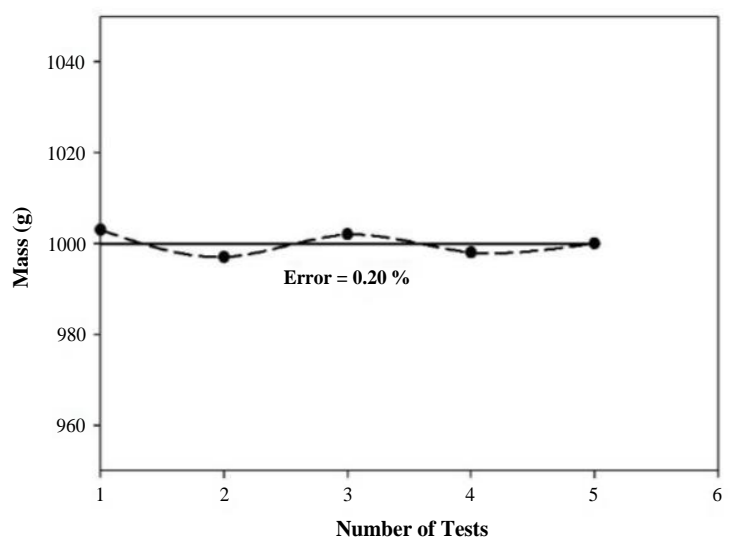

(c)

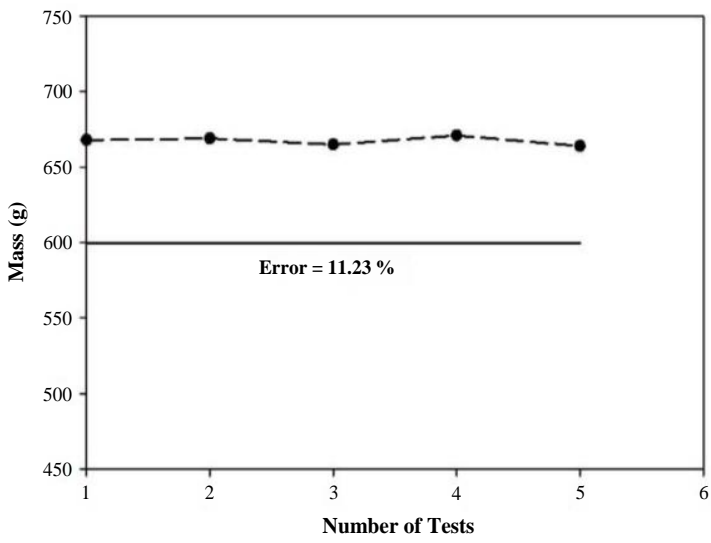

(b)

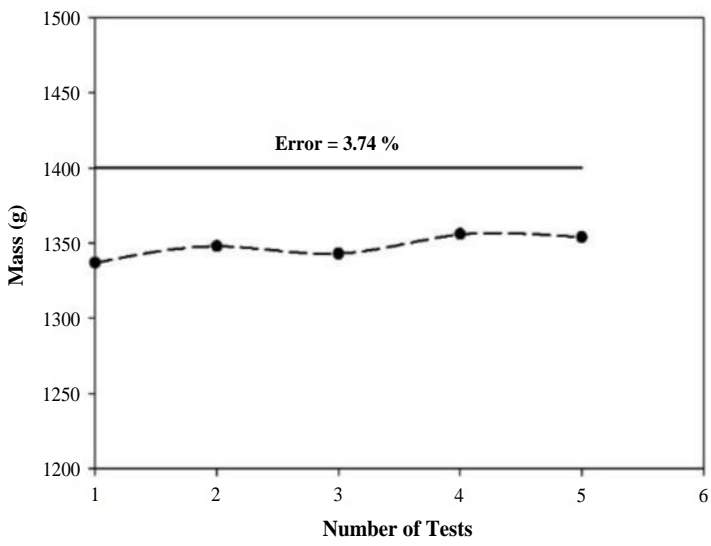

(d)

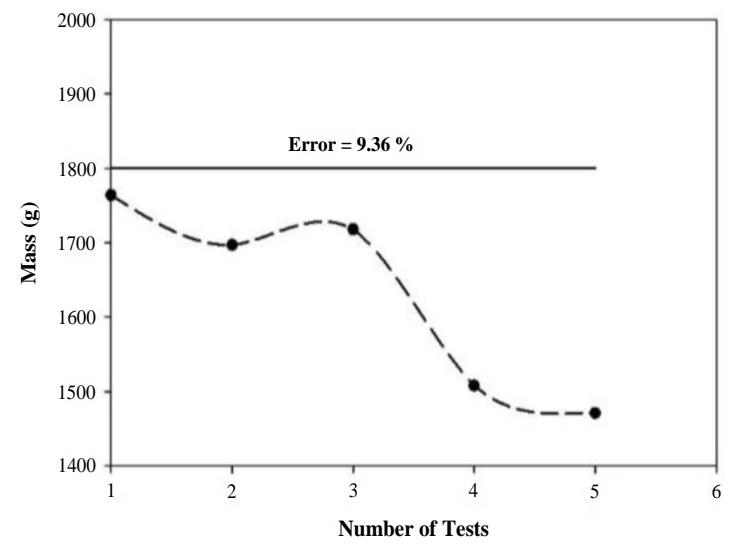

(e)

Figure 7. Mass measurement results at (a) 300g, (b) 600g, (c) 1000g, (d) 1,400g, and (e) 1,800g

Figure 7 shows $300 \mathrm{~g}$ produced a fairly large measurement error estimated at $19.6 \%$ due to the failure to design the light mass following the scale while the best result was obtained at $1000 \mathrm{~g}$ with the error approximated at $0.2 \%$. Meanwhile, at $1800 \mathrm{~g}$, the stability of the instrument was low as indicated by the discrepancy observed 5 times but its error was quite small at $9.36 \%$.

The measurement error is a comparison between the mass obtained from the measuring instrument with the actual value from a digital scale. It is mostly caused by several factors and an example is the uneven distribution of compressions of the four springs and this led to the occurrence of a small curvature on one side 
of the fiber optic and a larger one on the other side as shown in Figure 8. Moreover, the difference in the amount of warping affected the power losses produced. It can also be caused by the discrepancies between the results of the measurement and the model because the designs did not completely fit the mass measurement [24].

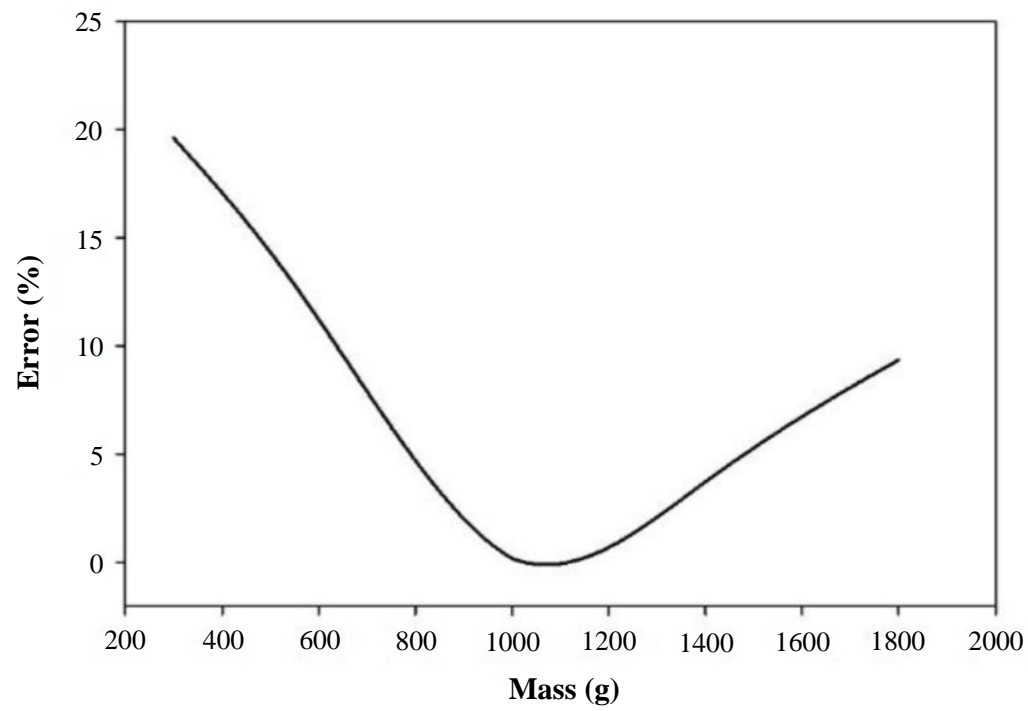

Figure 8. Error correction

The instrument was only effective in measuring loads with masses ranging from 600-1800g with a sensitivity of $50 \mathrm{~g}$ and at a wavelength source of $1550 \mathrm{~nm}$ but less effective below $600 \mathrm{~g}$ due to the significant error observed to be more than $10 \%$. Meanwhile, the stability of the instrument was found not to be good enough for masses above $1800 \mathrm{~g}$. Besides, the deviation between the measured data and the model designed was slightly large as indicated by the production of considerable measurement error [25].

\section{CONCLUSION}

The design and operation of the mass-scale instrument using optical fiber successfully produced the change of power losses directly proportional to the weight. The sigmoid graph showed the correlation coefficient $R^{2}$ for the wavelengths $1310 \mathrm{~nm}$ and $1550 \mathrm{~nm}$ were 0.9910 and 0.9959 , respectively. The instrument was also observed to have the ability to measure the range of mass from $600-1800 \mathrm{~g}$ with a better solution and sensitivity while the average measurement error was relatively small estimated at $10 \%$. Despite the significance of this error, the SMF design has a great potential to be used as an alternative to optically measure mass even beyond the range.

\section{ACKNOWLEDGMENTS}

The authors thanks to the Ministry of Education and Culture of Indonesia through Lembaga Penelitian dan Pengabdian Kepada Masyarakat, Universitas Riau, Pekanbaru for the generous and financial support provided for this research grant 2021.

\section{REFERENCES}

[1] P. S. Andre, "Modelling of Bend Losses in Single Mode Optical Fibers," Portugal: Aveiro University, 2006.

[2] Z. Xie, W. Shi, S. Fu, J. Yao, "Theoretical investigation of mode competition in high-power fiber lasers and amplifiers at 1018nm," Proceedings Advanced Laser Technology and Applications, vol. 10844, 2018.

[3] L. Meng, L. Wang, H. Xiong, H. Wang and X. Guo, " An investigation in the influence of helical structure on bend loss of pavement optical fiber sensor,” Optik, vol. 183, pp. 189-199, 2019.

[4] B. A. Tahir, J. Ali, Saktioto, M. Fadhali, R. A. Rahman and A. Ahmed, "A study of FBG sensor and electrical strain gauge for strain measurements," Journal of Optoelectronics and Advanced Materials, vol. 10, no. 10, pp. 2564 2568, 2008.

[5] S. Daud, M. A. Jalil, S. Najmee, Saktioto, J. Ali and P. P. Yupapin, "Development of FBG sensing system for outdoor temperature enviroment," Procedia Engineering, vol. 8, pp. 386-392, 2011.

[6] D. Irawan, T. Saktioto, J. Ali and P. Yupapin, "Design of Mach-Zehnder interferometer and ring resonator for biochemical sensing," Photonic Sensors, vol. 5, no. 1, pp. 12-18, 2015. 
[7] S. A. Kadhim, Z. A. Saleh and A. M. Raoof, "Performance Evaluation of Experimental Digital Optical Fiber Communication Link," International Journal of Innovative Research in Science, Engineering and Technology, vol. 6, no. 10, pp. 19534-19543, 2017.

[8] S. J. Choi, S. Y. Jeoung and J. K. Pan, "Intensity-Based Fiber Optic Sensor Head Characteristic Using Twist Dual Cycling Bending Loss," Advanced Photonics Congress (IPR, Networks, NOMA, PS, Sensors, SPPCom) OSA 2017, vol. 13, pp. 1-3, 2017.

[9] A. Martins, A. M. Rocha, B. Neto, A. L. J. Teixeira, M. Facao, R. N. Nogueira, M. J. Lima and P. S. Andre, "Modeling of Bend Losses in Single-Mode Optical Fibers," FTC through FEFOF (PTDC/EEA-TEL/72025/2006) project, 2009.

[10] M. Lemlem, "Investigation of the Effects of Macro Bending Loss on Step Index Single Mode Fiber," Ethiopia: Addis Ababa University, 2012.

[11] M. S. John, "Optical Fiber Communications Principles and Practice,” England, 2009.

[12] R. T. Schermer and J. H. Cole, "Improved bend loss formula verified for optical fiber by simulation and experiment," IEEE Journal of Quantum Electronics, vol. 43, no. 10, pp. 899-909, 2007.

[13] L. A. Ribeiro, J. B. Rosolem, D. C. Dini, C. Floridia, E. W. Bezerra, F. A. Cezar, M. D. Loichate and A. S. Durelli, "Optical fiber sensor for pressure measurement based on elastomeric membrane and macrobending loss," Optical Sensing and Detection II, vol. 8439, no. 1-9, 2012.

[14] D. Irawan, T. Saktioto, J. Ali and M. Fadhali, "Birefringence analysis of directional fiber coupler induced by fusion and coupling parameters," International Journal for Light and Electron Optics, vol. 124, no. 17, pp. 3063-3066, 2013.

[15] T. Saktioto, J. Ali, M. Fadhali, R. A. Rahman, J. Zainal, "Modeling of coupling coefficient as a function of coupling ratio," Proceedings of SPIE - The International Society for Optical Engineering, vol. 7155, pp. 1-10, 2016.

[16] D. Derickson, "Fiber Optic Test and Measurement," Upper Saddle River, NJ: Prentice Hall, 1997.

[17] S. Arun, V. Choudhury, V. Balaswamy, R. Prakash and V. R. Supradeepa, "High power, high efficiency, continuous-wave supercontinuum generation using standard telecom fibers," Optics Express, vol. 26, no. 7, pp. 16, 2018.

[18] R. K. Ula, D. Hanto, T. B. Waluyo, H. Adinanta and B. Widiyatmoko, " Design of micro bending deformer for optical fiber weight sensor," 2nd International Symposium on Frontier of Applied Physics (ISFAP 2016), IOP Publishing IOP Conf. Series: Journal of Physics: Conf. Series, vol. 817, no. 012050, pp. 1-6, 2017.

[19] H. -F. Hu, S. -J. Sun, R. -Q. Lv and Y. Zhao, "Design and experiment of an optical fiber micro bend sensor for respiration monitoring," Sensors and Actuators A: Physical, vol. 251, pp. 126-133, 2016.

[20] P. P. Yupapin, T. Saktioto and J. Ali, "Photon trapping model within a Fiber Bragg Grating for dynamic optical tweezers use," Microwave and Optical Technology Letters, vol. 52, no. 4, pp. 959-961, April 2010.

[21] S. S. Chong, A. R. A. Aziz and S. W. Harun, "Fibre optic sensors for selected wastewater characteristics," Sensors, vol. 13, no. 7, pp. 8640-8668, 2013.

[22] B. Tian, K. Li, Z. Zhang, F. Han, N. Zhao, Q. Lin, Z. Jiang, "Optical fiber MEMS micro pressure sensor based on beam-membrane structure," IEEE 14th International Conference on Nano/Micro Engineered and Molecular Systems (NEMS), pp. 135-138, 2019.

[23] A. A. Amanum, "Effects of macro bending losses in single mode step index fiber," International Journal of Advanced Engineering Research and Applications, vol. 2, no. 6, pp. 348-356, October 2016.

[24] U. Stanley, V. M. Olu, C. Ochonogor, A. Peter and A. Francis, "Experimental analysis of cable effect on signal attenuation in single and multimode fiber optics," International Journal of Electrical and Computer Engineering (IJECE), vol. 8, no. 3, pp. 1577-1582, 2018.

[25] S. M. Saimon, N. H. Ngajikin, M. S. Omar, M. H. Ibrahim, M. Y. M. Noor, A. S. Abdullah and M. R. Salim, "Alow-cst fiber based displacement sensor for industrical applications," Telkomnika, vol. 17, no. 2, pp. 555-560, 2019.

\section{BIOGRAPHY OF AUTHORS}

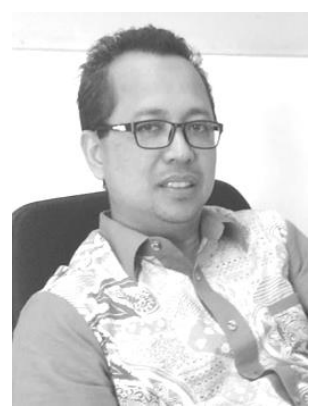

Toto Saktioto is a Professor of Physics Dept., Faculty of Mathematics and Natural Sciences, Universitas Riau, Pekanbaru, Indonesia. He works on Plasma and Photonics Physics. He has published many articles and supervised Master and Doctoral degree since 2009. Currently his research focus is phonics and plasma industry for communication and biosensors. 

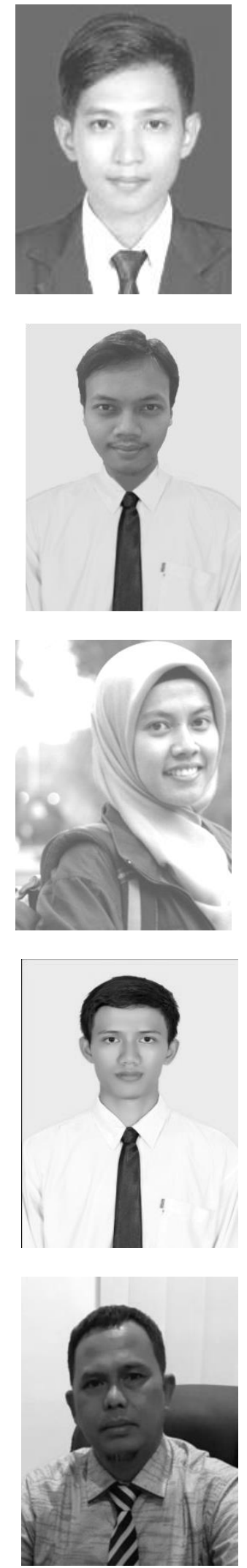

Wahyu Candra completion his B.Sc. study in Department of Physics of Universitas Riau on 2019. Currently he is a graduate student in Magister Physics in Universitas Riau with focus study on photonic and fiber optics.

Yan Soerbakti is a undergraduate student in Department of Physics of Universitas Riau with focus study on optical physics.

Vepy Asyana is a lecturer at Physics Department, Faculty of Mathematics and Natural Sciences, Universitas Riau, Pekanbaru, Indonesia. She was completion undergraduate and graduate study in Universitas Riau and Bandung Institute of technology in 2012 and 2016, both in Physics Study . Currently her research focus is instrumentation and computational physics.

Romi Fadli Syahputra is graduate student at Universitas Riau and completion his B.Sc. study in Dept. of Physics Universitas Riau on 2016. His interest works include applied and pure physics.

Syamsudhuha is a Senior lecturer at Mathematic Department, Faculty of Mathematics and Natural Sciences, Universitas Riau, Indonesia. He works on Optimization and Computational Mathematics. He has published many articles and supervised Master and currently, he officiates as the Dean of Faculty of Mathematics and Natural Sciences, Universitas Riau. 


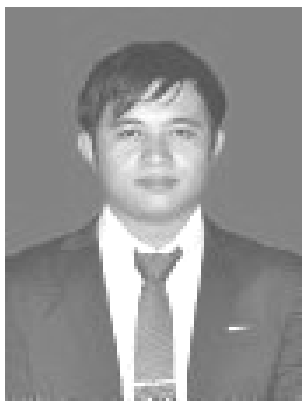

Dedi Irawan is a lecturer at Physics Education, Dept. of Education of Mathematics and Natural Sciences, Universitas Riau, Pekanbaru, Indonesia. He works on basic and advanced Photonics. He has published many articles and supervised Master degree since 2019.

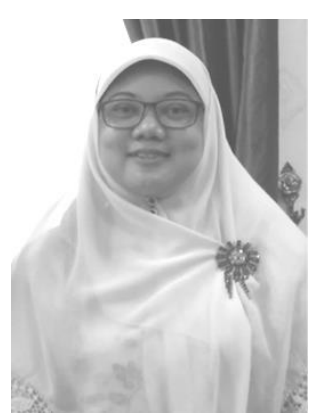

Okfalisa is a Senior at Department of Informatics Engineering, UIN Sultan Syarif Kasim Riau,. She was obtained doctorate degree from Information System at Universiti Teknologi Malaysia (UTM) in 2011. Her interests are in knowledge management system, knowledge base, expert system and information system.

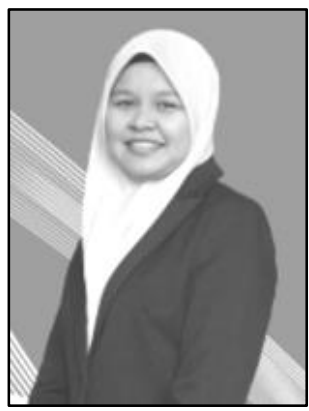

Haryana Hairi is lecturer in Universiti Teknologi Mara (UiTM) Malaysia. She complete her physics Ph.D in Universiti Teknologi Malaysia in 2011. Her specializations are laseroptoelectronics / photonics, plasma technology, and optics.

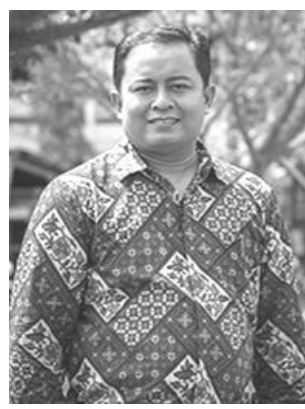

Dadang Syarif Shihabudin Sahid is a Senior lecturer at system information study of Politeknik Caltex Riau. He was competence on web programming, system development and aplication, it project management. 